Coo-3056-25

Thermo

Electron

CORPORATION

OISTRIBUTION OF THIS OOCUMENT IS UNLIMITED 


\section{DISCLAIMER}

This report was prepared as an account of work sponsored by an agency of the United States Government. Neither the United States Government nor any agency Thereof, nor any of their employees, makes any warranty, express or implied, or assumes any legal liability or responsibility for the accuracy, completeness, or usefulness of any information, apparatus, product, or process disclosed, or represents that its use would not infringe privately owned rights. Reference herein to any specific commercial product, process, or service by trade name, trademark, manufacturer, or otherwise does not necessarily constitute or imply its endorsement, recommendation, or favoring by the United States Government or any agency thereof. The views and opinions of authors expressed herein do not necessarily state or reflect those of the United States Government or any agency thereof. 


\section{DISCLAIMER}

Portions of this document may be illegible in electronic image products. Images are produced from the best available original document. 


\title{
ERDA/NASA \\ ADVANCED THERMIONIC \\ TECHNOLOGY PROGRAM \\ PROGRESS REPORT NO. 23
}

May 1977

NASA Contract NAS3-20302

ERDA Contract EY-76-C-02-3056

\author{
Prepared by \\ Thermo Electron Corporation \\ 101 First Avenue \\ Waltham, Massachusetts 02154
}


ii 
Representatives of Thermo Electron participated in the NASA/ERDA

Thermionic Program Review which was held in conjunction with the 1977 IEEE International Conference on Plasma Science. Three papers concerning the Thermo Electron thermionic effort were presented at the IEEE Conference:

"Experiments with Enhanced Mode Thermionic Converters" by P. E. Oettinger and F. N. Huffman.

"Thermionic Converter Plasma Analysis" by C. C. Wang and J. Keck

"Emitter and Collector Development for Thermionic Converters" by D. Lieb, A. Sommer, T. Briere, C. Balestra and D. Goodale. 


\section{SURFACE STUDIES}

\section{A. SURFACE THEORY}

No work was performed on this task during this reporting period.

\section{B. BASIC SURFACE EXPERIMENTS}

Heat treatments of a high density pellet of lanthanum hexaboride, obtained from Cerac Inc., were performed in the Surface Characterization Chamber. The pellet was held by a doublewasher clamp arrangement using rhenium washers. This sample had a substantial amount of calcium present at the surface, which had not been observed in any of the $\mathrm{LaB}_{6}$ samples previously analyzed. Results of this heat treatment study are summarized in Table I-1. The $\mathrm{B} / \mathrm{La}$ ratios after heat treatment are the highest observed for any $\mathrm{LaB}_{6}$ samples analyzed in the chamber. After discussions with Dr. Edmund Storms, it appears that the as-synthesized $\mathrm{LaB}_{6}$ material had a stoichiometric excess of bor on and that the congruent vaporization composition, which results in a low $\mathrm{LaB}_{6}$ work function, was not obtained because of insufficient heat treatment. This result is consistent with Cerac's use of free boron as a sintering agent.

\section{DIRECT BEAM CHAMBER}

Cesium "channels" were installed to replace the cesium reservoir in order to provide for more convenient operation. A molybdenum sample was used in an initial test and $T / T_{R}$ curves were obtained over a limited cesium pressure range. A minimum work function of $1.6 \mathrm{eV}$ was measured at $\mathrm{T} / \mathrm{T}_{\mathrm{R}}=2.0$. 
TABLE I- 1

ANALYSIS OF HEAT TREATMENT

OF HIGH DENSITY LaB 6

\begin{tabular}{|l|c|c|c|c|}
\hline \multirow{2}{*}{$\begin{array}{c}\text { Chemical } \\
\text { Specie }\end{array}$} & $\begin{array}{c}\text { As } \\
\text { Received } \\
(\%)\end{array}$ & $\begin{array}{c}5 \text { Min. } \\
1273 \mathrm{~K} \\
(\%)\end{array}$ & $\begin{array}{c}1 \text { Min } \\
1473 \mathrm{~K} \\
(\%)\end{array}$ & $\begin{array}{c}15 \mathrm{Sec} \\
1573 \mathrm{~K} \\
(\%)\end{array}$ \\
\hline $\mathrm{B}$ & 14 & 67 & 64 & 60 \\
\hline $\mathrm{C}$ & 28 & 2.6 & 12 & 17 \\
\hline $\mathrm{N}$ & 1.0 & & & \\
\hline $\mathrm{O}$ & 23 & 5.5 & 1.5 & 1.1 \\
\hline $\mathrm{S}$ & 1.1 & 1.6 & & \\
\hline $\mathrm{Ca}$ & 11 & & & \\
\hline $\mathrm{Cr}$ & 7.9 & & & 2.4 \\
\hline $\mathrm{La}$ & 13 & 25 & 22 & 2.91 \\
\hline $\mathrm{B} / \mathrm{La}$ & 1.08 & 2.68 & 2.9 & \\
\hline$\phi_{\mathrm{e}}$ & & & & \\
\hline
\end{tabular}


The experiment was repeated with three fare earth hexaborides; viz, $\mathrm{LaB}_{6}, \mathrm{YB}_{6}$ and $\mathrm{EuB}_{6}$. The sintered hexaboride samples (purchased from Cerac) were mounted on a rhenium base. In all three cases the minimum work functions were above $2 \mathrm{eV}$. On cesium oxygen alternation the work functions of $\mathrm{LaB}_{6}$ and $\mathrm{YB}_{6}$ were reduced to 1.3 to 1.4 $\mathrm{eV}$, but the work function of $\mathrm{EuB}_{6}$ remained high.

These work functions are higher than those obtained in earlier experiments with hexaborides in the Activation Chamber in which sprayed powdered material was used. Auger Spectroscopy has shown that such powders are much purer than sintered material. However, even a standard barium oxide cathode produced an abnormally high work function, which may indicate contamination of the pump system. Attempts are being made to resolve these problems. 


\section{PLASMA STUDIES}

\section{A. CONVERTER THEORY}

Convergence of the value describing the electron energy flux in the sequential integration of the plasma equations has been achieved. Solutions were obtained for a cesium vapor converter operated in the ignited mode with an emitter temperature of $1800 \mathrm{~K}$, a collector temperature of $700 \mathrm{~K}$, cesium pressures of 1 and 2 tor $r$, a spacing of 10 mils and a range of current ratios $\mathrm{J} / \mathrm{J}_{\mathrm{E}}$.

Sample results showing the dependence of the plasma parameters (function $\phi=n k\left(T_{e}+T_{i}\right)\left[\right.$ where $n$ is electrons $/ \mathrm{cm}^{3}, k$ is the Boltzmann constant in units of $\mathrm{eV} / \mathrm{K}$, and $\mathrm{T}_{e}$ and $\mathrm{T}_{i}$ are the temperatures of electrons and ions, respectively], potential $\psi$, and electron temperature $\mathrm{T}_{\mathrm{e}}$ ) on position in the diode are presented in Figure II- 1 for a saturation current of $1.5 \mathrm{~A} / \mathrm{cm}^{2}$ and a current ratio of 0.77 . Vertical dashed lines indicate the location of the electrodes. The upper curve shows that the peak of the function $\phi$ is closer to the emitter, and that the extrapolated distance $d_{e x}{ }^{\circ}$ at the emitter side is about twice the value of that at the collector side. The middle curve indicates that the difference of potential between the emitter and collector boundaries is small. The lower curve shows that, except near the boundaries, the electron temperature distribution decreases linearly from the emitter to the collector. The larger drop in the electron temperature near the collector boundary is probably due to the loss of hot electrons through the sheath.

The variations of $\phi$ for the selected values of current ratio $\mathrm{J} / \mathrm{J}_{\mathrm{E}}$ are shown in Figure II-2. These data demonstrate that the plasma density increases as the current ratio increases. In Figure II- 3 the variation of the electron temperature, $\mathrm{T}_{e}$, and the potential, $\psi$, as a function of current ratio is presented. 


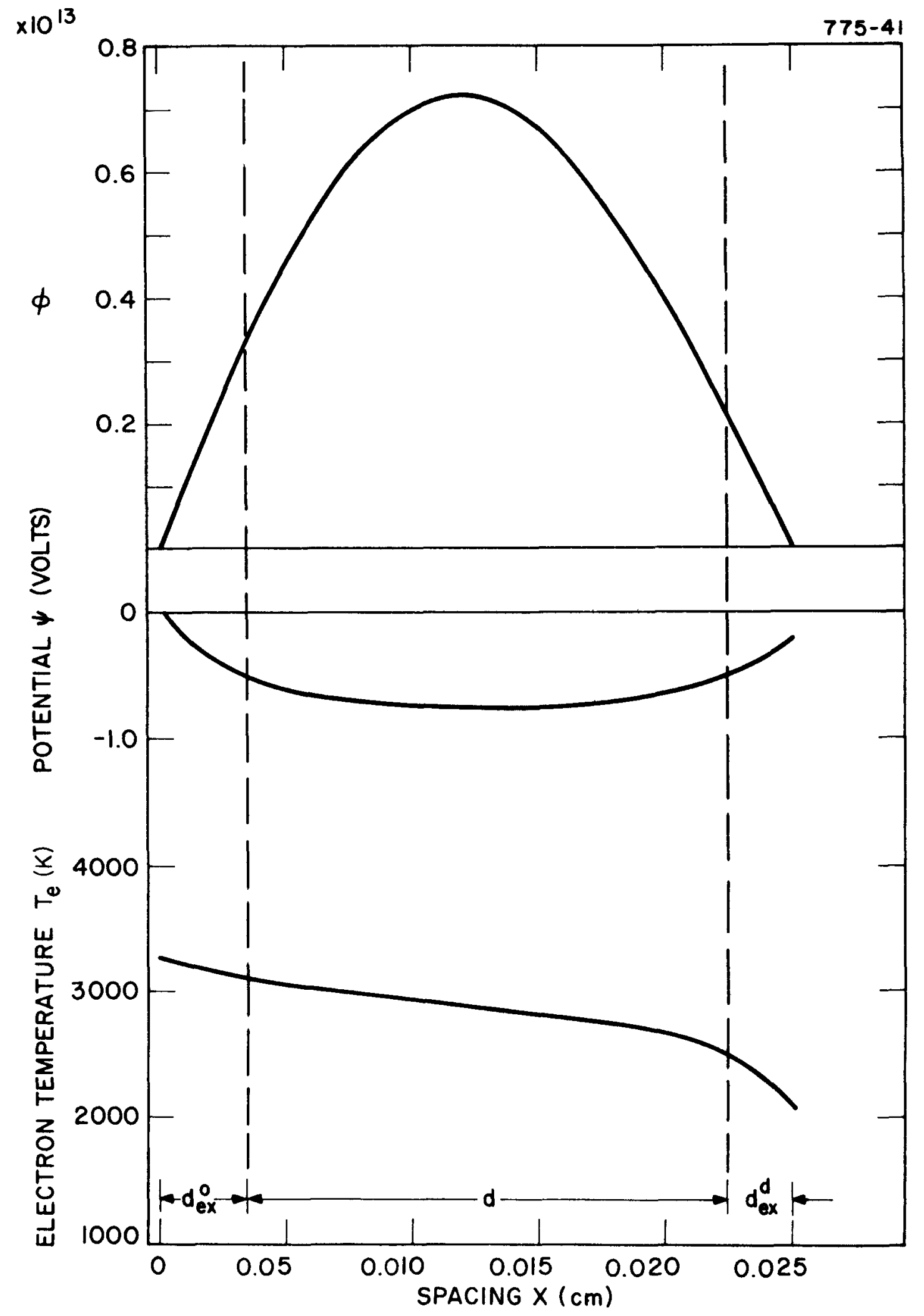

Figure II- 1. Plasma Parameters as a Function of Variable $\psi$ 
$775-42$

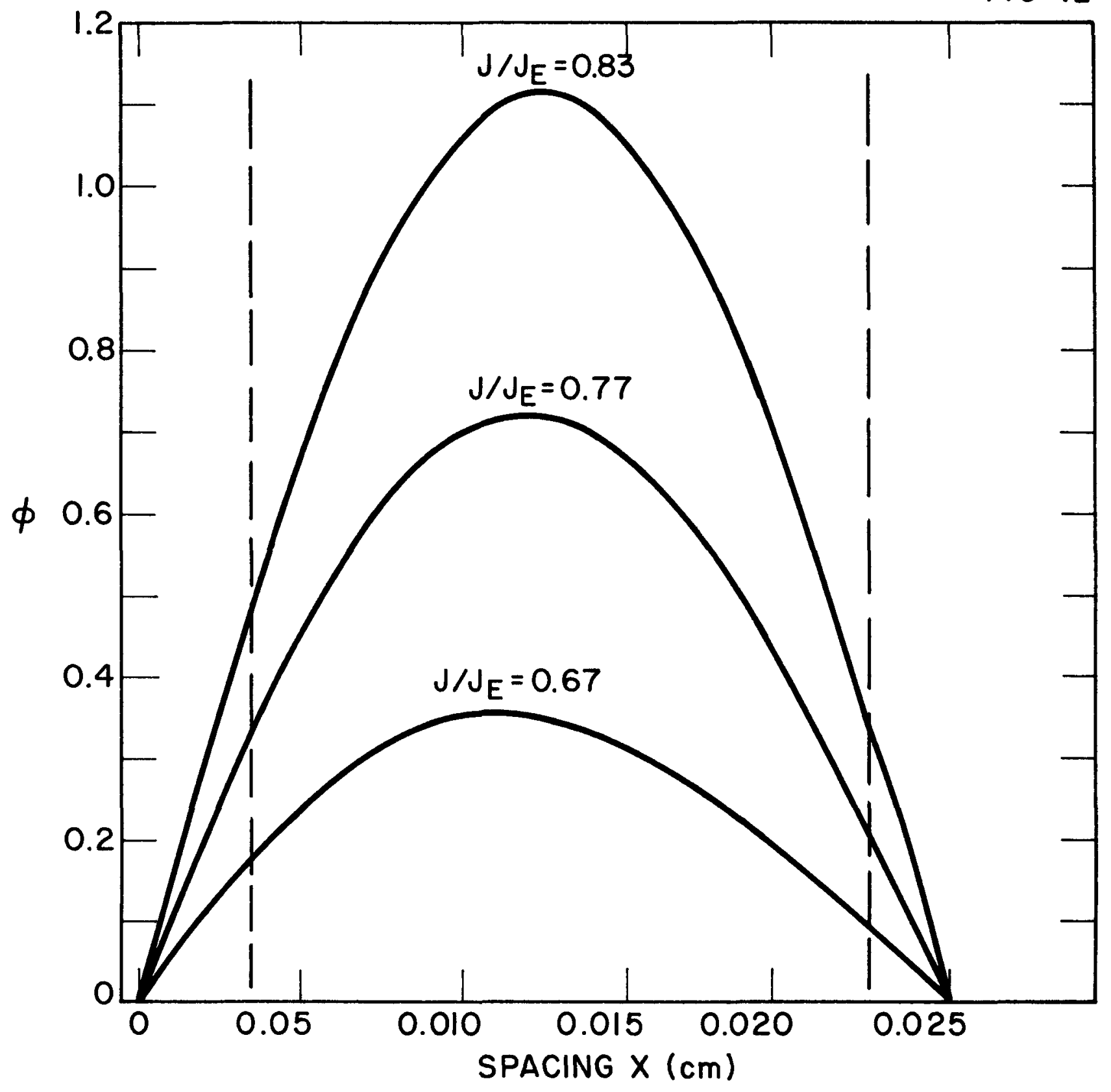

Figure II-2. Comparison of Function $\phi$ as a Function of Current Ratio 


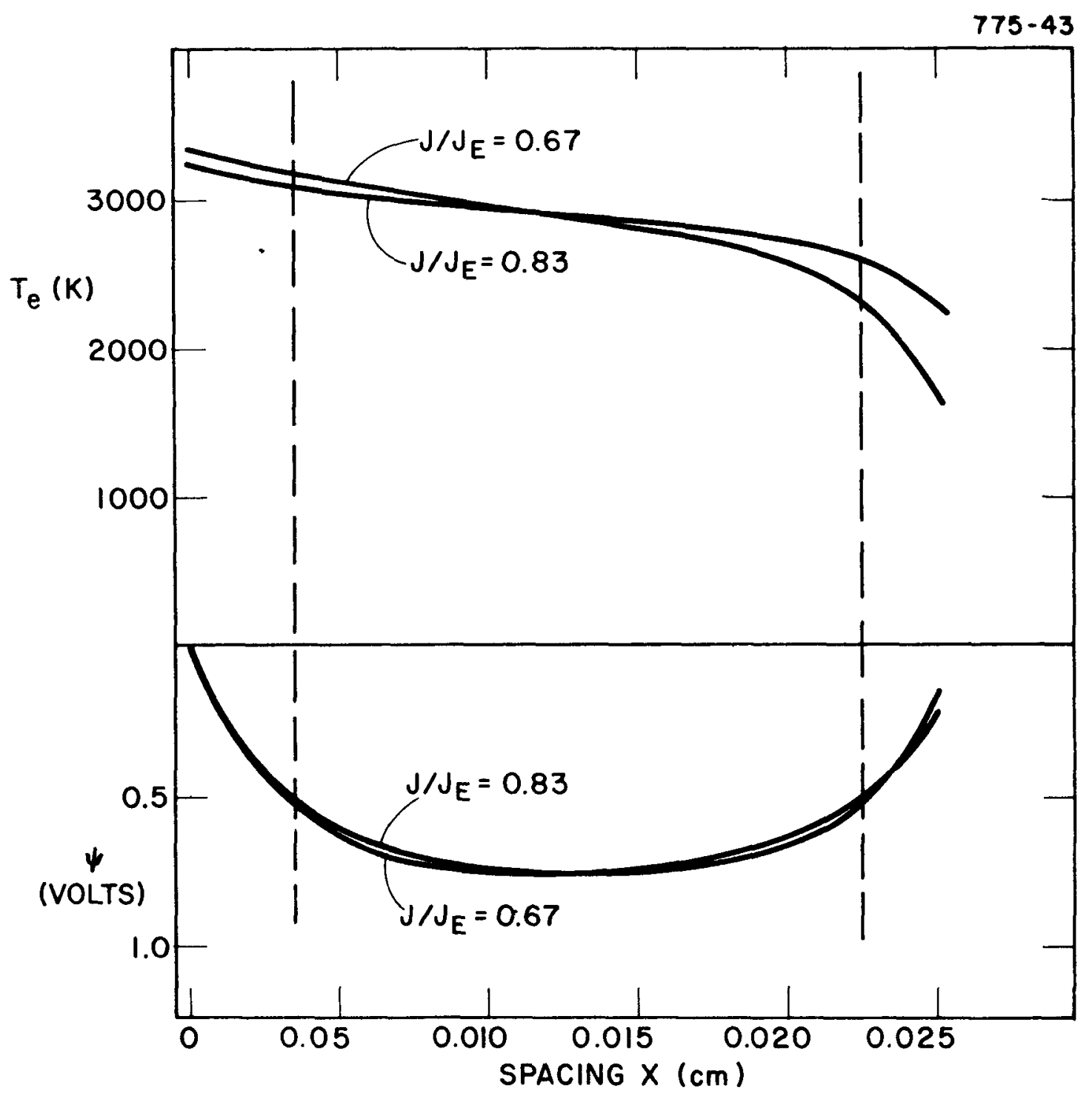

Figure II-3. Comparison of Potential, $\psi$, and Electron Temperature, $T_{e}$, as a Function of Current Ratio, $\mathrm{J} / \mathrm{J}_{\mathrm{E}}$ 
Changes in this ratio produce only slight perturbations in the potential; however, the electron temperature distribution becomes significantly more uniform as the current increases.

It is interesting to compare these results to the same case except that the diode saturation current is increased to $2.8 \mathrm{~A} / \mathrm{cm}^{2}$ (see Figures II-4 and II-5). These results also indicate that the plasma density is strongly dependent on the current and that the changes of electron temperature and potential function are relatively small.

The effects of cesium vapor pressure on the plasma parameters are shown in Figure II- 6 , for a saturation current of $2.8 \mathrm{~A} / \mathrm{cm}^{2}$ and a current ratio of 0.75 . Since the increase of pressure reduces the charged particle mobility, a higher plasma density is required to carry the same amount of current. This increase of pressure also reduces the electron temperature, whereas the change of potential, $\psi$, is relatively small.

The arc drop is shown in Figure II- 7 as a function of the current ratio. Most of the arc drop is due to the difference in sheath height. The contribution from the potential difference in the plasma is relatively small. The dashed line is the first order result using the constant electron temperature approximation.

From these results the following conclusions were drawn:

(1) For a converter operated with the product of pressure and spacing ( $p d$ ) values between 7 and 17 mil-tor $r$, the contribution of the potential difference in the plasma to the arc drop is small. 


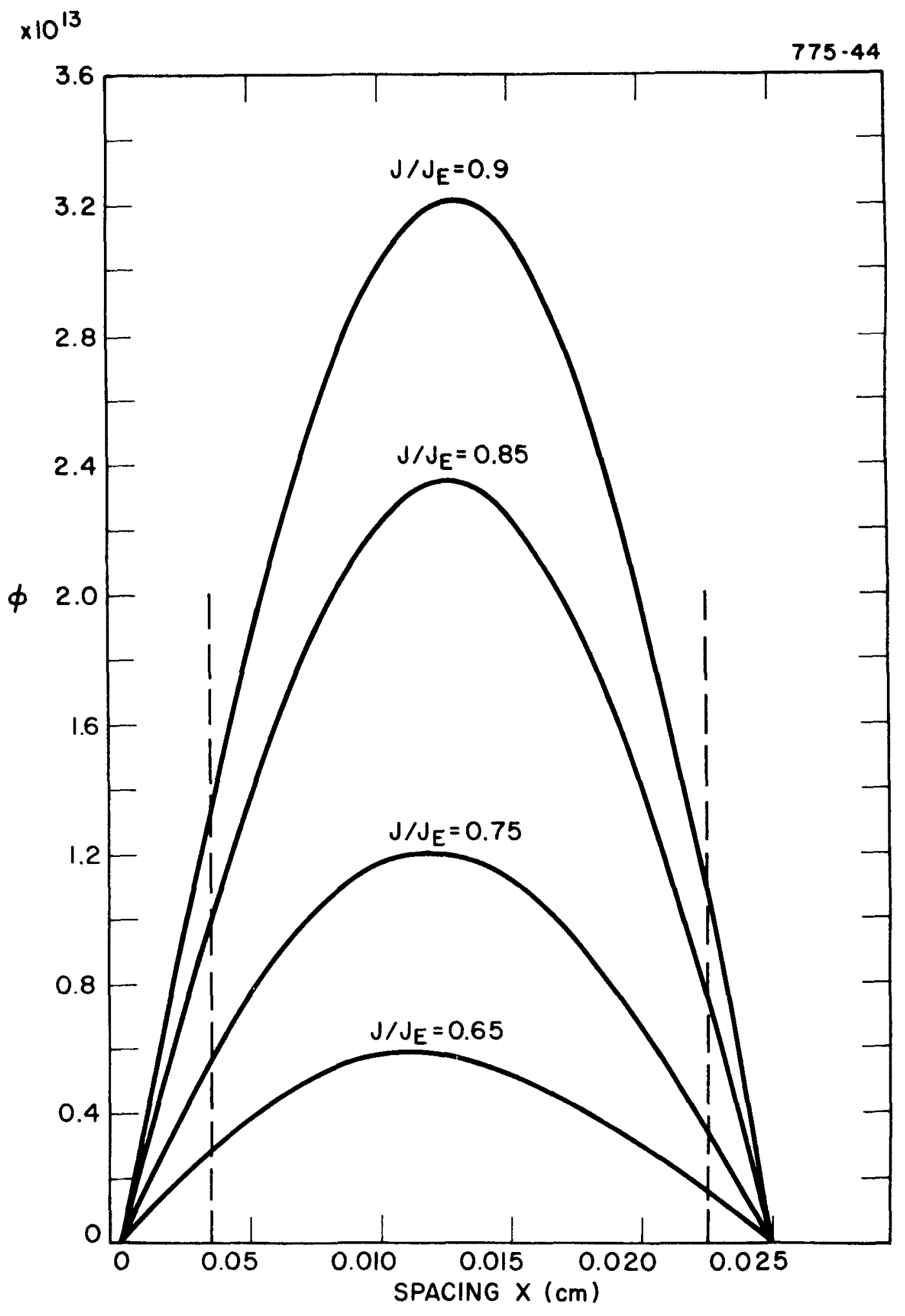

Figure II-4. Comparison of Function $\phi$ of Current Ratio $\mathrm{J} / \mathrm{J}_{\mathrm{E}}$ with the Value of Saturation at $2.8 \mathrm{~A} / \mathrm{cm}^{2}$ 


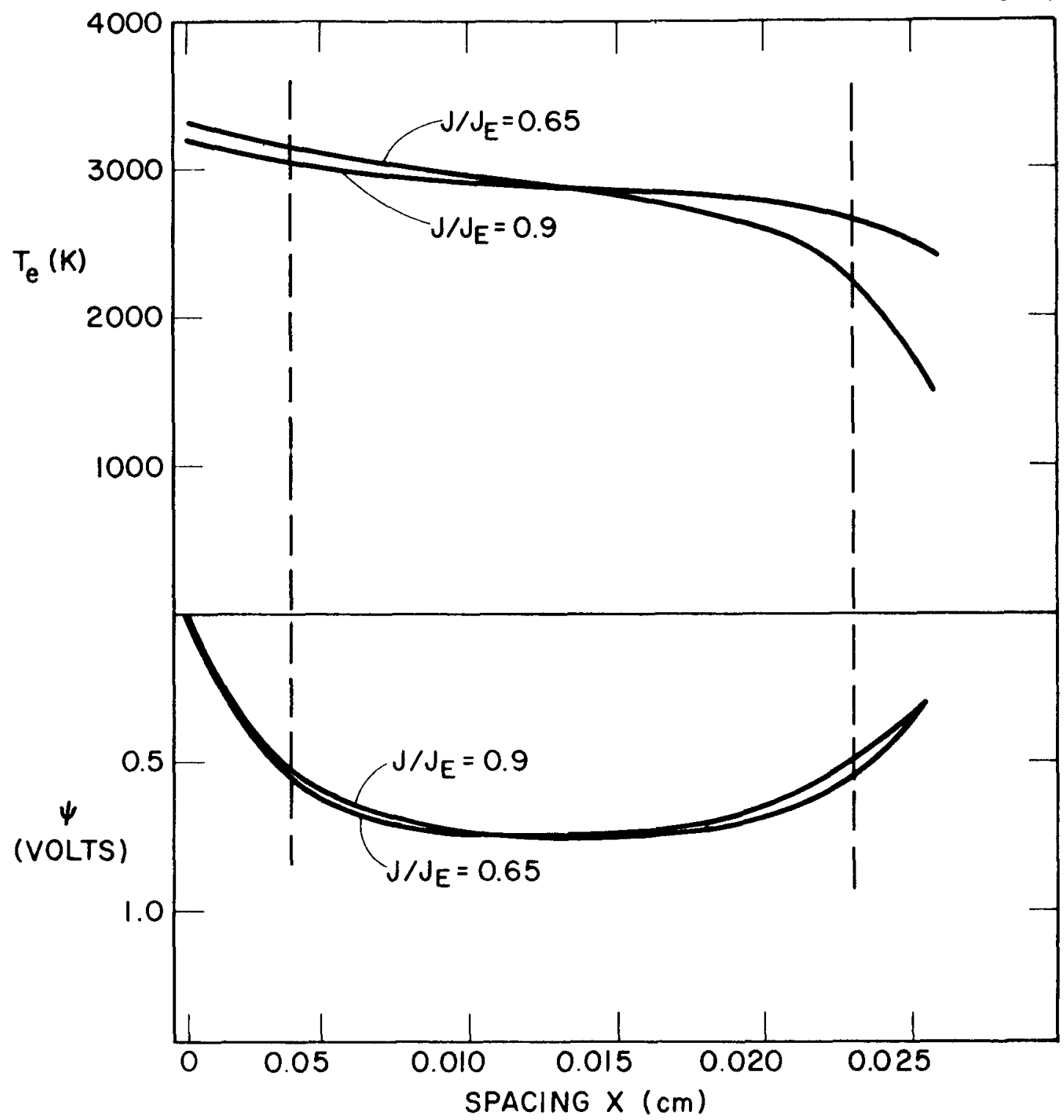

Figure II-5. Comparison of Electron Temperature $\mathrm{T}_{\mathrm{e}}$ and Potential $\psi$ as a Function of Current Ratio $\mathrm{J} / \mathrm{J}_{\mathrm{E}}$ with the Saturation Current at $2.8 \mathrm{~A} / \mathrm{cm}^{2}$ 


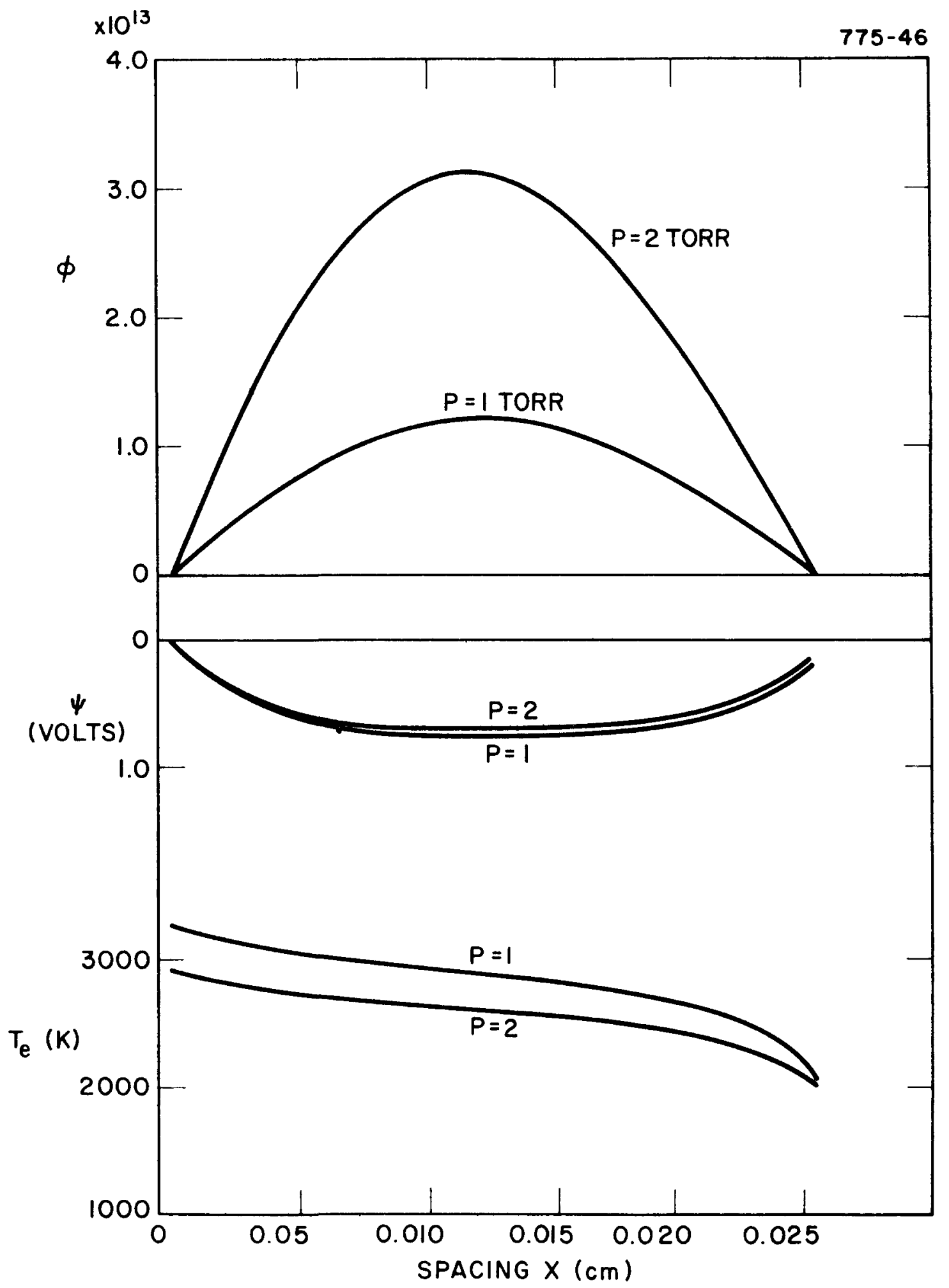

Figure II-6. The Effect of Cesium Vapor Pressure On Plasma Parameters 


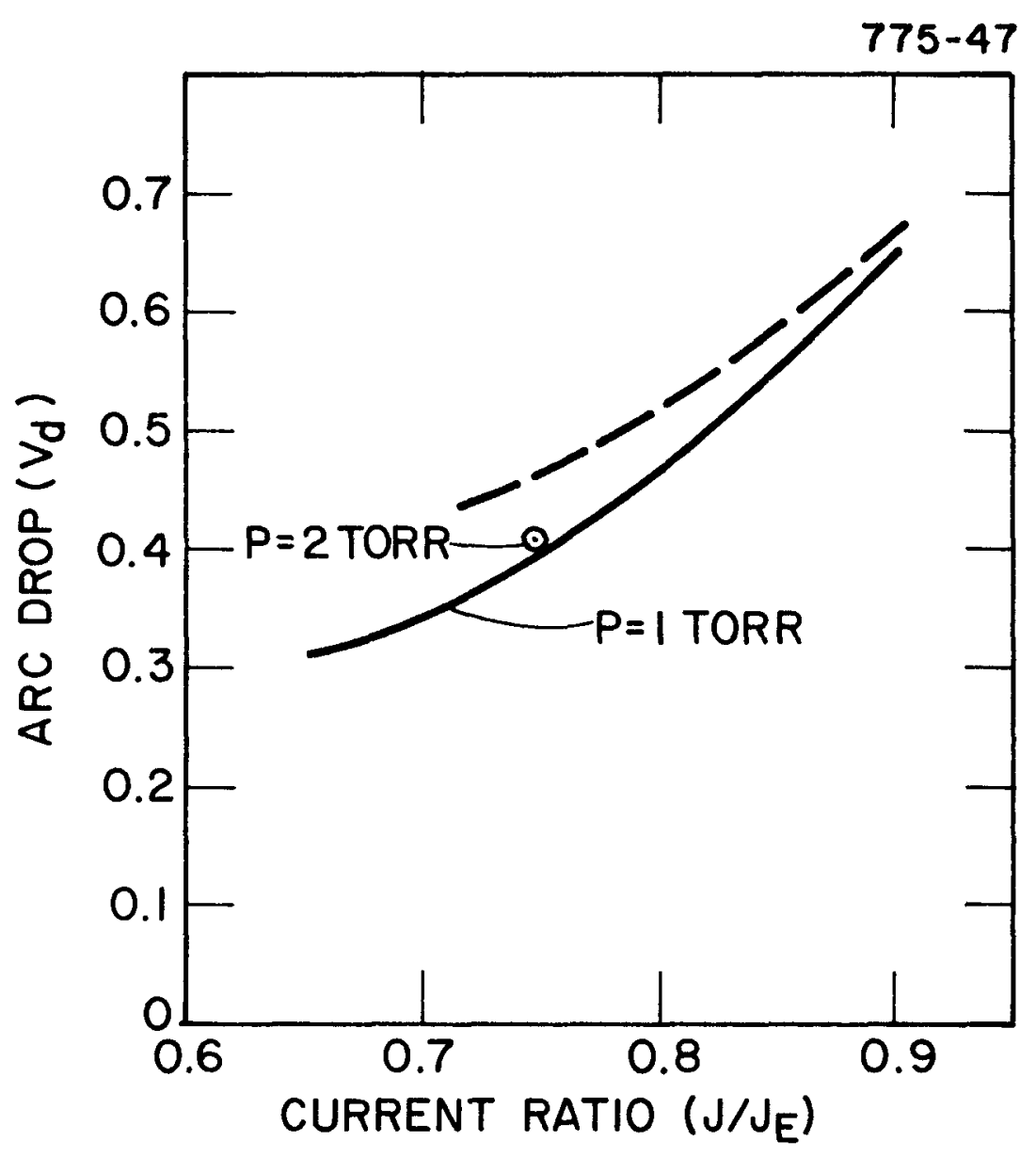

Figure II-7. Arc drop as a function of current Ratio $\mathrm{J} / \mathrm{J}_{\mathrm{E}}$. 
(2) The spatial distribution of electron temperature has a significant effect on the arc drop.

B. ENHANCED MODE CONVERSION EXPERIMENTS

The paper presented at the IEEE 1977 International Conference on Plasma Science detailed the results obtained with a pulsed ring triode. Apparently, uniform discharges were produced with emittercollector spacings as low as $0.5 \mathrm{~mm}$. Enhanced output power was obtained at cesium pressures up to 0.5 torr. 


\section{COMPONENT DEVELOPMENT}

\section{A. LOW TEMPERATURE CONVERSION EXPERIMENTS}

\section{Converter No. 170 - Barium Oxide Thin Film Diode}

This standard variable spacing converter employed an electropolished tungsten emitter fitted with a platinum cap. The collector was a standard nickel structure covered by a thin film of barium oxide. This barium oxide film, approximately $800 \AA$ thick, was evaporated onto the emitter subassembly. After final welding and outgassing, the emitter was heated to $1673 \mathrm{~K}$ to reevaporate the film onto the nickel collector structure. Prior to reevaporation onto the collector, dc emission measurements indicated an emitter work function of about $2.8 \mathrm{eV}$ with no cesium present in the converter, confirming the fact that barium oxide was still on the emitter surface. However, after reevaporation dc backemission measurements did not indicate any change in the work function of the collector.

The diode was subsequently cesiated and power data were taken. At emitter temperatures of $1300 \mathrm{~K}$ and $1400 \mathrm{~K}$ a large barrier index was observed. Testing was terminated and the converter was opened. The interior indicated that at some time during testing the platinum cap had separated from the tungsten emitter body. Auger analysis of the electrode surfaces showed that substantially all the barium oxide had been transferred onto the collector. No traces of platinum were found on the collector. 


\section{B. HIGH EFFICIENCY CONVERTER EXPERIMENTS}

1. Converter No. 162 Tungsten Emitter Columbium 1\% Zirconium Tungsten Oxide Collector

After 2200 hours of operation this converter was shut down in order to check the emitter thermocouples for degradation effects. The emitter temperature was measured optically through the bell jar with a pyrometer just prior to the shut down. Losses due to deposits on the bell jar were included in this measurement. Subsequent calibration of the bell jar showed the emitter temperature to be $30^{\circ}$ high, which at $1600 \mathrm{~K}$ would result in a positive $50-\mathrm{mV}$ shift in the I-V curve (see Figure III- I).

At this time the converter was moved to a dc life-test station. The initial performance was poor but steadily improved over a period of several days. A power failure inadvertently caused the emitte $\mathrm{r}$ to cool down while the collector remained at $850 \mathrm{~K}$ for several hours. Upon reheating the emitter, the performance was found to have decreased, and it appeared that the converter had lost oxygen. Electrode spacing had to be reduced to $10 \mathrm{mils}$ in order to obtain the current density previously measured at 40 mils. The performance remained low over the next several days, and cycling the collector to high temperatures failed to release any oxygen to the emitter. However, after burning off whiskers that had formed on the electrode there was some indication of oxygen enhancement giving an output power density of $2.5 \mathrm{~W} / \mathrm{cm}^{2}$ at 0.3 volts. The shorting problems associated with the whiskers disappeared, enabling the spacing to be opened to 40 mils (see Figue III-2). Testing will continue on this converter. 
774-1

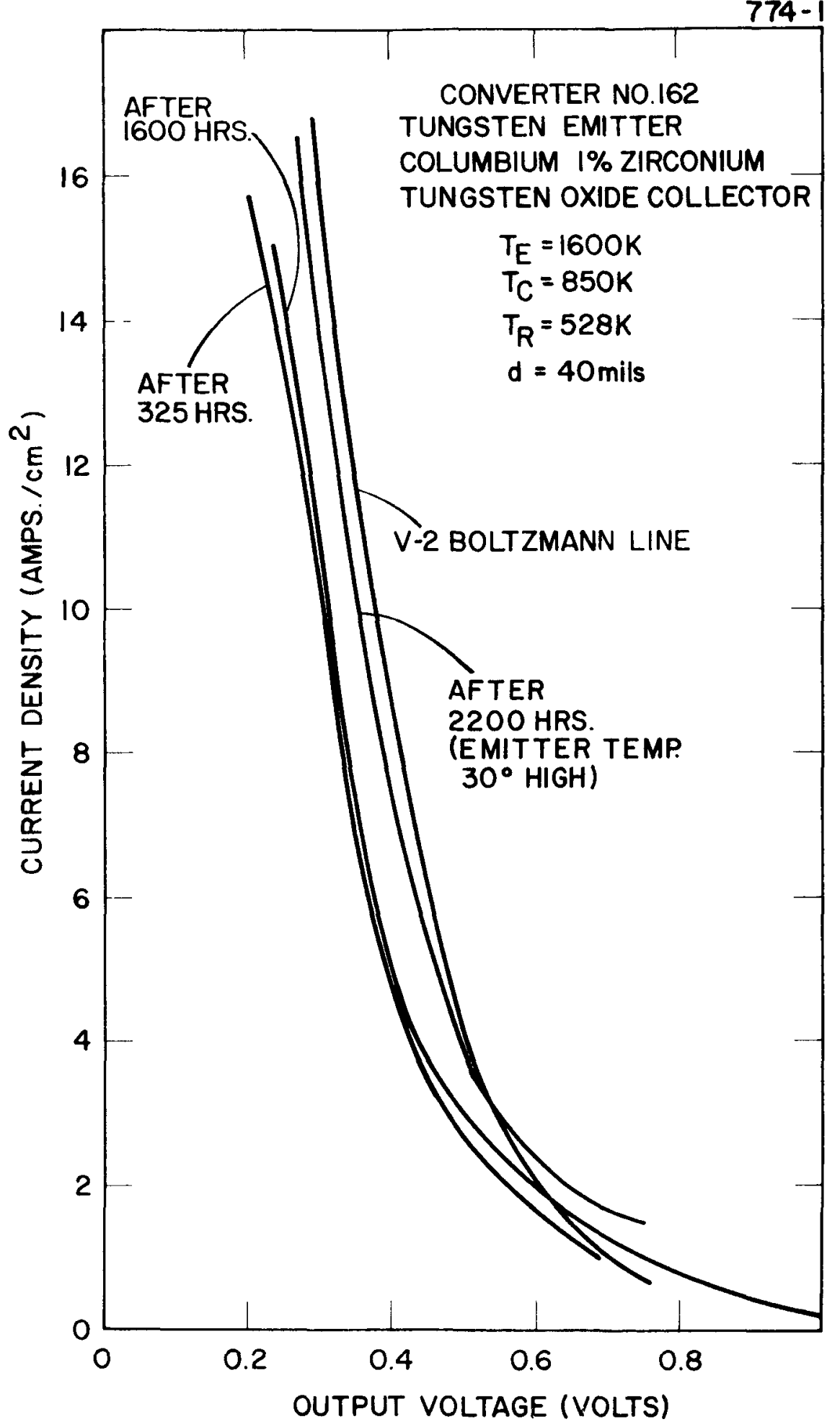

Figure III-1. Converter Performance During Life Test 


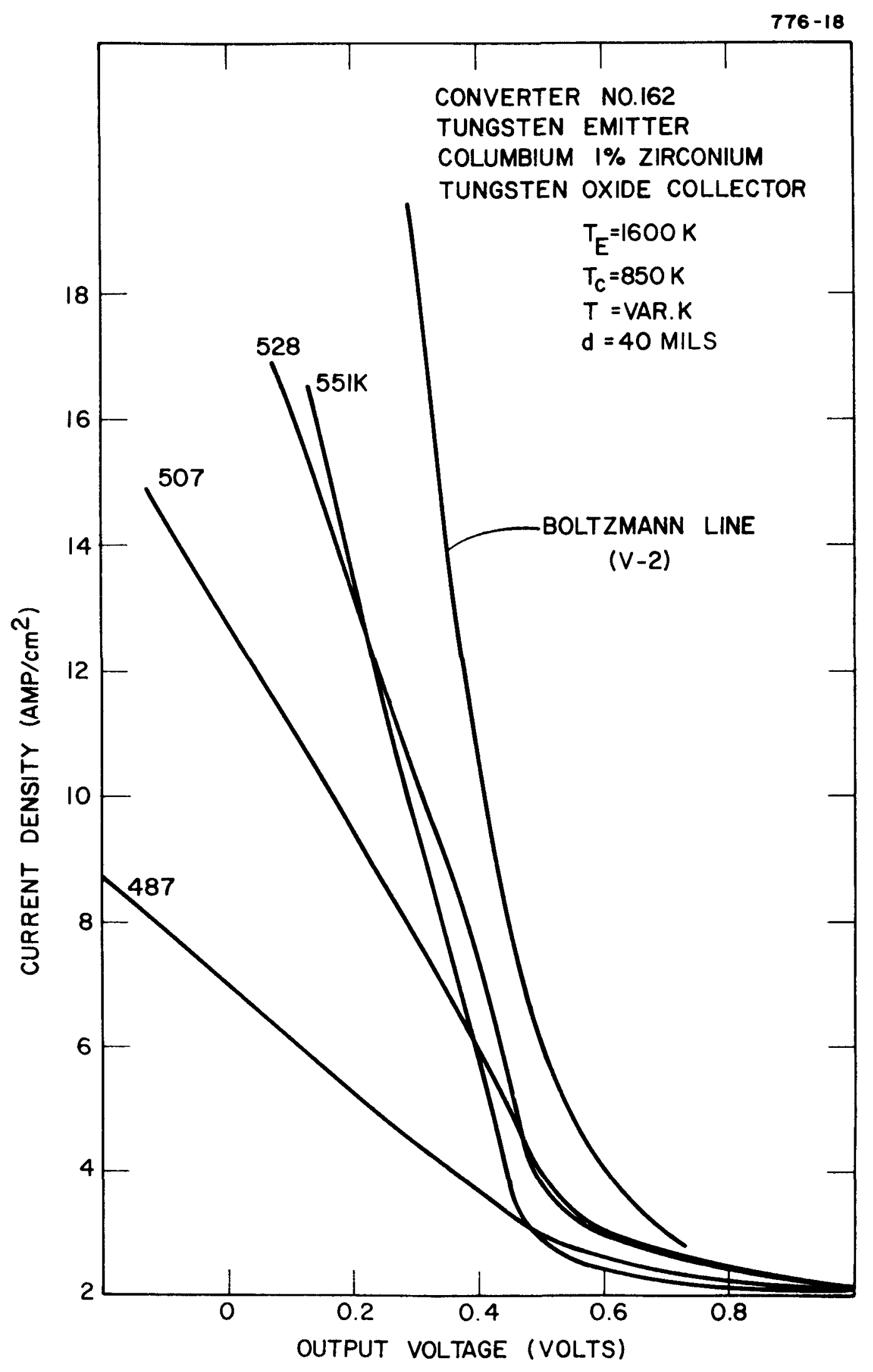

Figure III-2. Cesium Family "Oxygenated Performance" 
2. Converter No. $168 \mathrm{LaB}_{6}$ Emitter LaB 6 Collector

Both the emitter and collector for this diode were fabricated from sintered $\mathrm{LaB}_{6}$ obtained from Cerac. This material had a density of $98.69 \%$ of that theoretically determined for solid LaB 6 . To form the collector, first a molybdenum substrate was copper/nickel brazed to the standard nickel collector body and then a disk of $\mathrm{LaB}_{6}$ was nickel brazed to the molybdenum. Since the collector during converter operation never exceeds temperatures of $1000 \mathrm{~K}$ this method of brazing is adequate. However, at this time no satisfactory method has been devised for brazing $\mathrm{LaB}_{6}$ to tungsten to allow it to withstand emitter temperatures between 1300 and $1800 \mathrm{~K}$.

In order to construct the emitter for this converter, a disk of LaB $_{6}$ was set on a bed of rhenium wires inside a cup machined in the end of a standard tungsten emitter (see Figure III-3). Electrical contact is made by the rhenium tie wires, which also serve to hold the disk snugly in place. The $\mathrm{LaB}_{6}$ disk is heated by radiation from the tungsten emitter and its temperature is measured by reading a black body hole sighted through a sapphire window. Rhenium wire was used since it does not appear to react with $\mathrm{LaB}_{6}$ as most other metals do at elevated temperatures.

Initially, an attempt was made to run the converter in the ignited mode in order to determine the emitter work function from the saturated emission current. However, observation through the window showed that the discharge did not occur between the two LaB 6 electrodes, but rather from the edge of the tungsten emitter to the collector body. Emitter temperatures and cesium pressures were varied over a wide range in an effort to find conditions where the discharge could be maintained between the electrodes; unfortunately, no such conditions were found. It is assumed that in the ignited mode the tungsten 


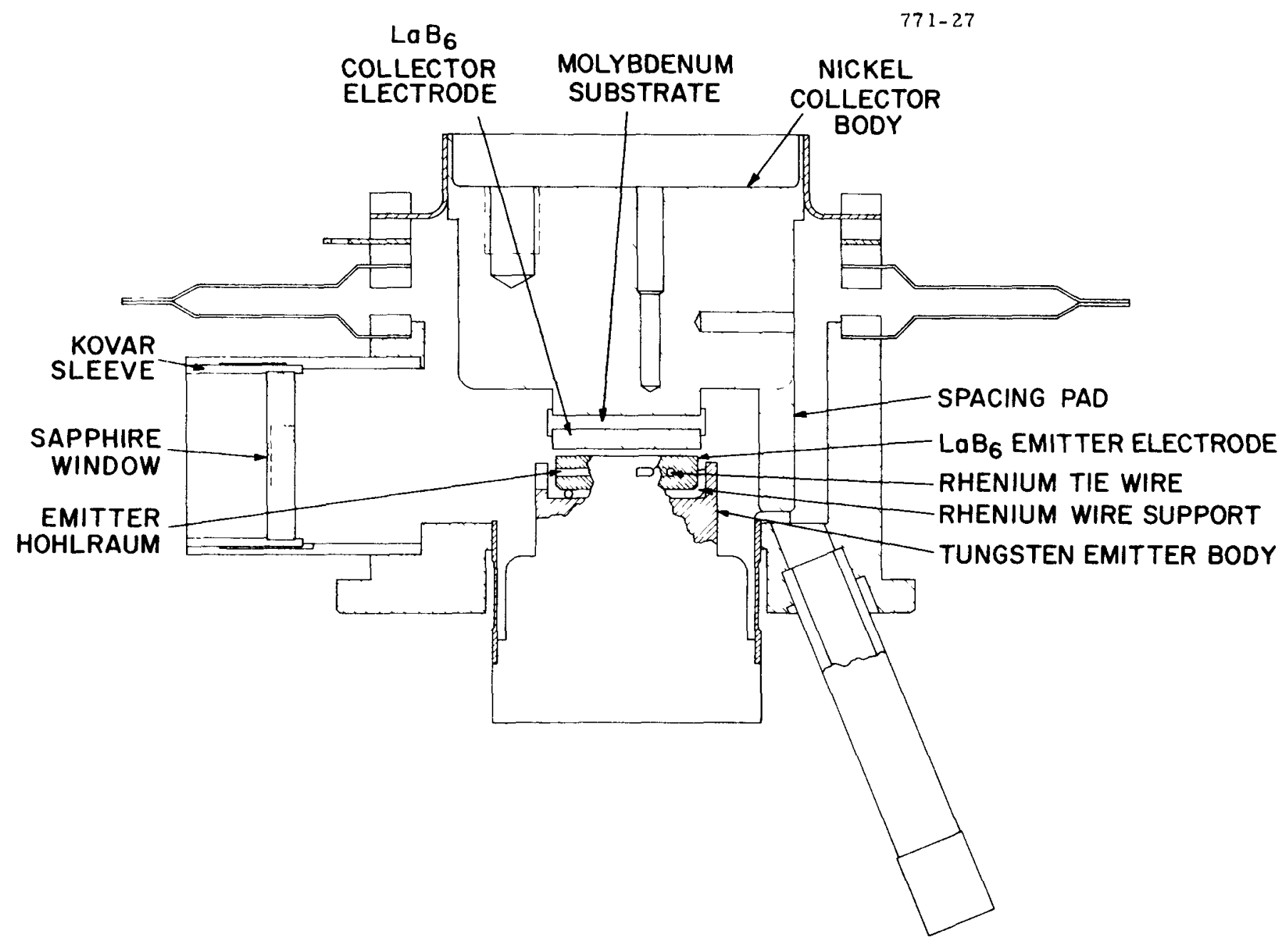

Flgure III-3. Converter No. 168 
emitter body always provided a higher saturation current than was produced by the $\mathrm{LaB}_{6}$. It should be noted that the emitter body was always about $250^{\circ}$ hotter than the $\mathrm{LaB}_{6}$.

In operating the converter in the unignited, or lower, mode it was possible to distinguish between currents emitted from the tungsten emitter body and the $\mathrm{LaB}_{6}$. The I-V curve in this mode had a double saturation; one part from the tungsten emitter and one part from the LaB $_{6}$ disk (see Figure III-4). The lower right-hand part of the curve on first saturation is emission from the tungsten. This part of the curve is independent of spacing indicating that the electrodes cannot be brought close enough together to affect the space charge. The upper left-hand part of the curve, or second saturation, is spacing dependent, rising rapidly as the $\mathrm{LaB}_{6}$ electrodes are brought together. Since the retarding regions of the two saturations occur at different output voltages, it implies that the two emitter surfaces are at different temperatures, which is indeed the case. One would expect this behavior since the Boltzmann line has shifted due to the difference in temperature. Assuming the collector has a single work function value, the knee at the higher output voltage represents current from the hotter surface. Emitter work functions were determined by taking the difference in current between the two saturations and assuming this was emission

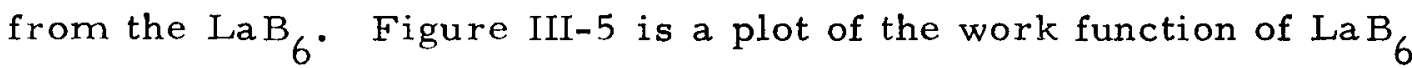
versus $T_{E} / T_{R}$ for several emitter and reservoir temperatures, and Figure III- 6 shows how LaB $_{6}$ compares to several other emitter materials. 
$775-54$

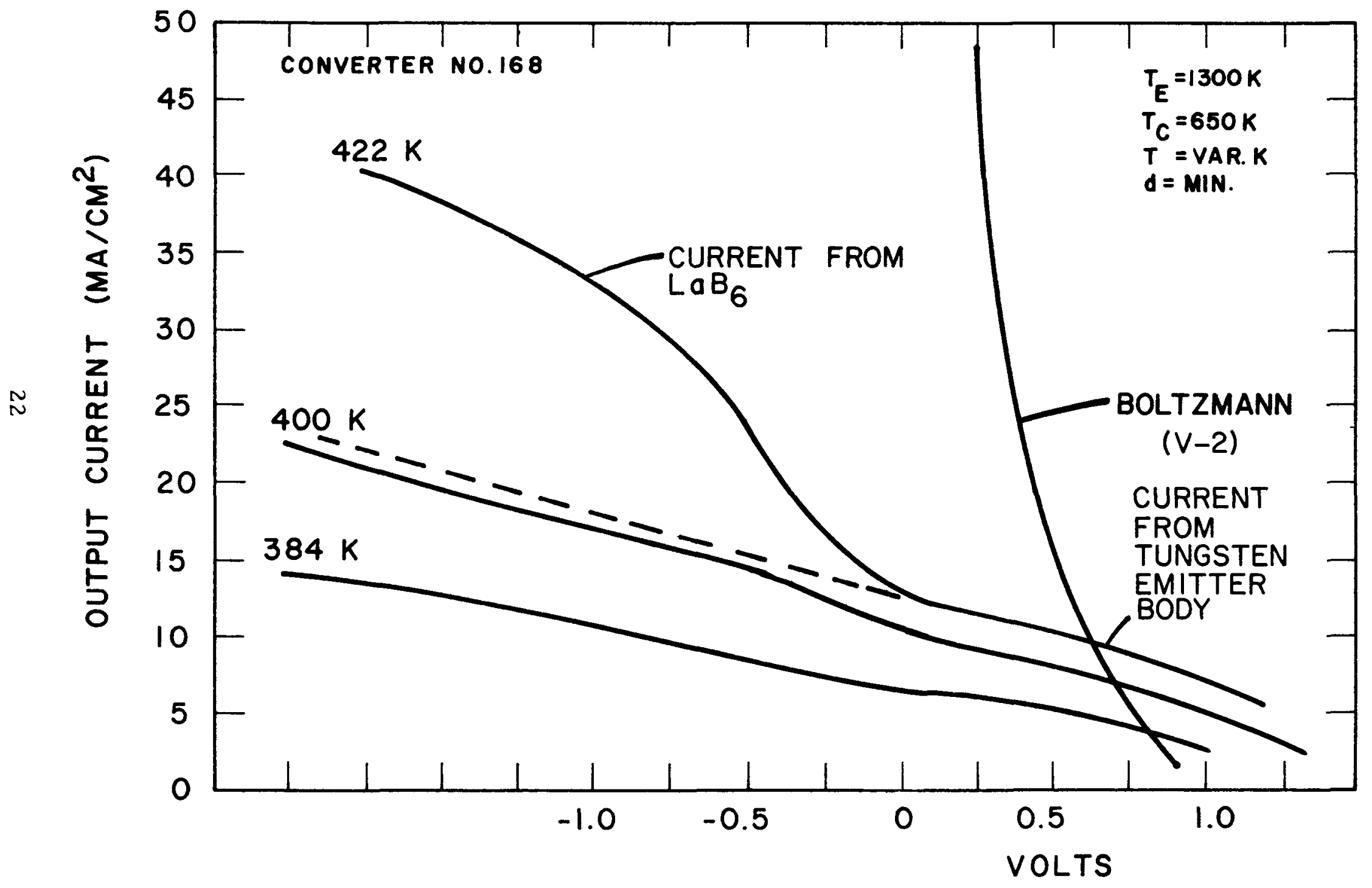

Figure III-4. Lower Mode Current with double saturation 


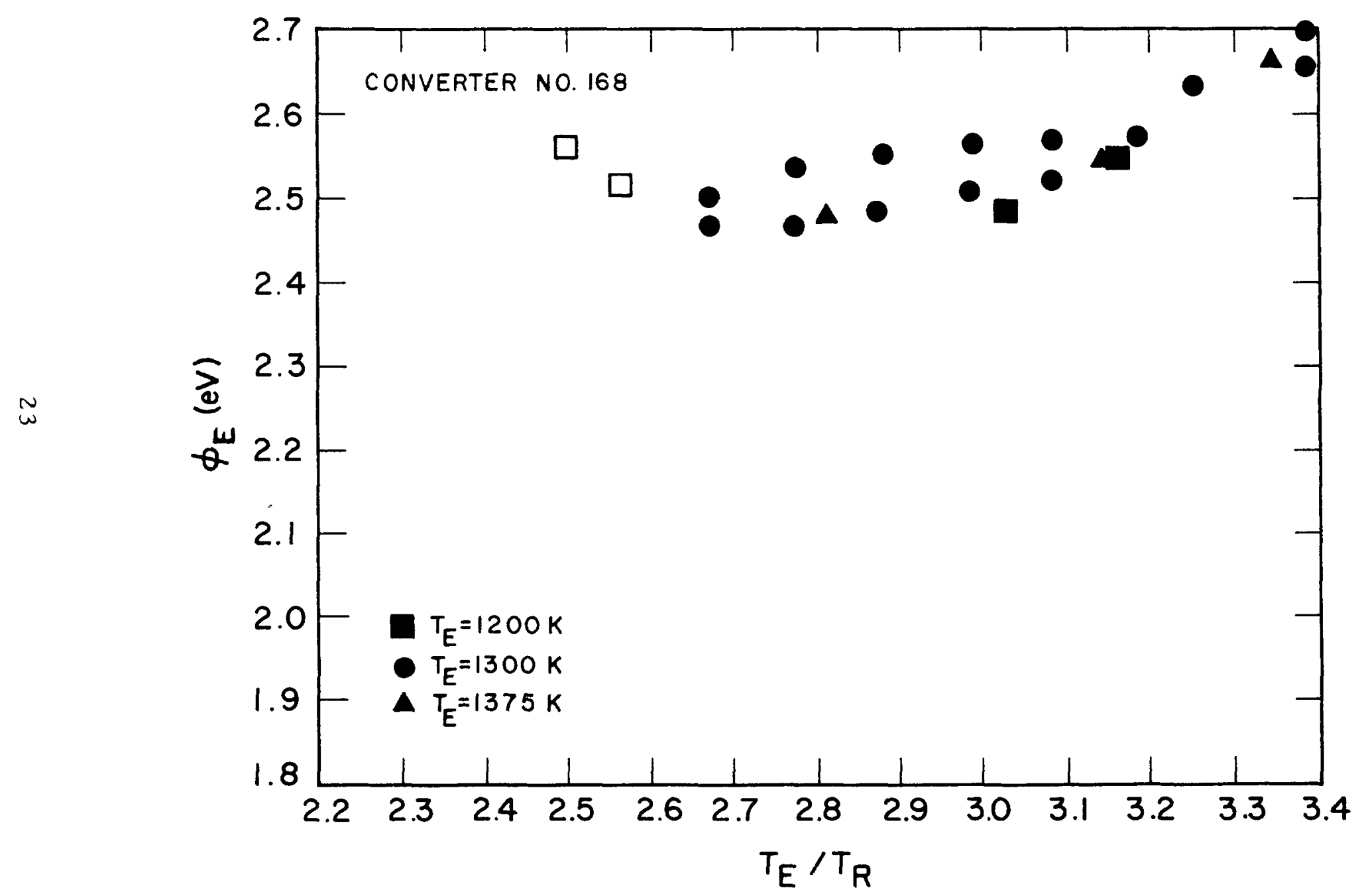

Figure III-5. Lanthanium Hexaboride Work Function 


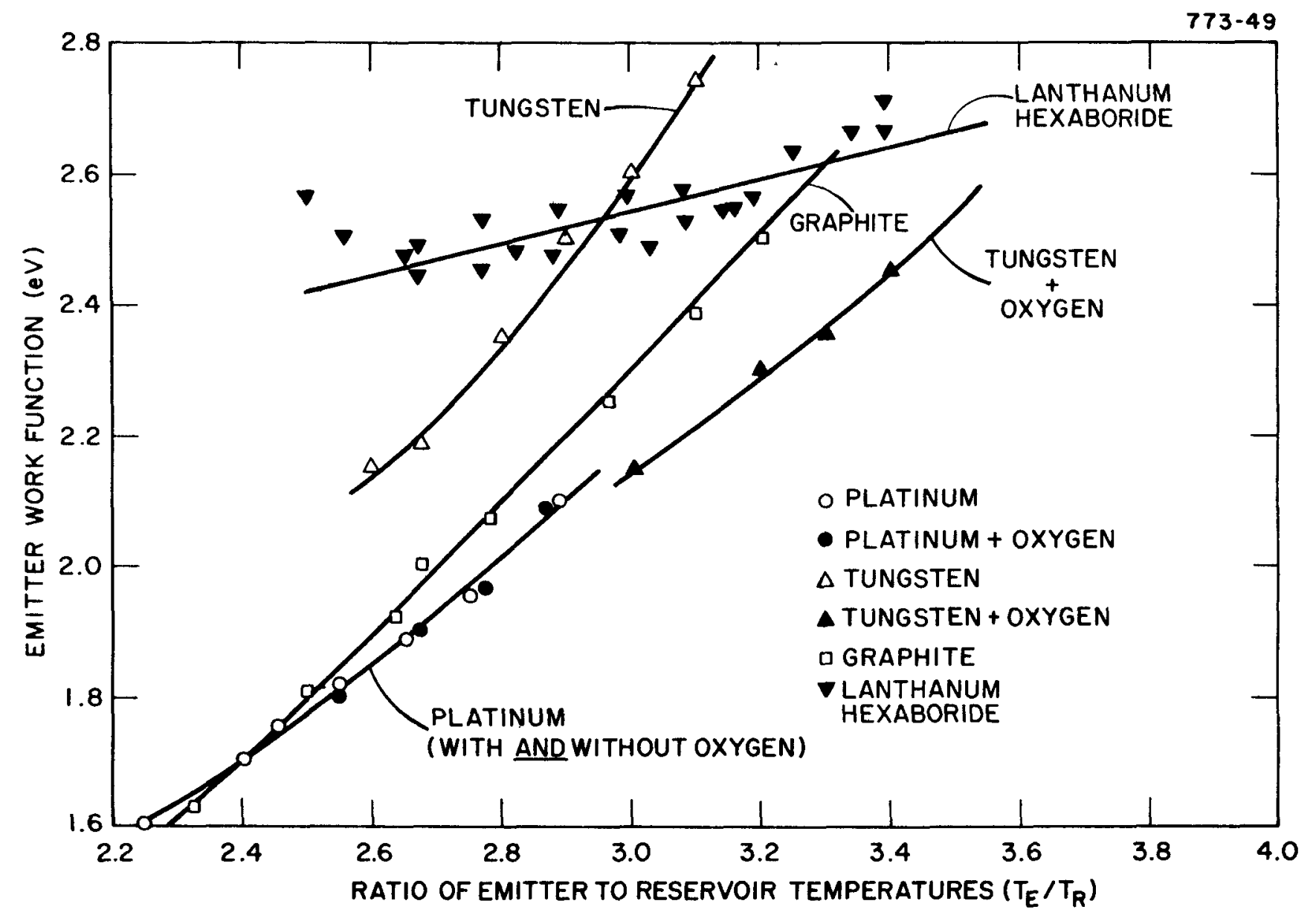

Figure III-6. Work Function of Various Emitter Surfaces vs $T_{E} / T_{R}$ 


\section{COMPONENT HARDWARE PROGRAM}

\section{A. HOT SHELL DEVELOPMENT}

Ten silicon carbide hot shells were fabricated.

A preliminary design was made of a reactor for growing tungsten hot shell liners by chemical vapor deposition from tungsten hexafluoride. This design, depicted in Figure IV- 1 is based on the reactor used by Battelle Memorial Institute in the fabrication of tungsten-lined hot shells. The growth environment consists of a flow-sustained mixture of hydrogen and tungsten hexafluoride maintained at about $650 \mathrm{C}$. Total pressure inside the reactor is to be maintained at about 5 torr or less.

On May 25, 1977, Dr. C. L. Balestra visited the laboratory of Prof. R. I. Diefendorf, at the Materials Research Center of Rensselaer Polytechnic Institute (RPI). This laboratory is studying the effect of growth parameters upon residual internal stress in as-grown silicon carbide. Silicon carbide is grown at reduced pressure (5 - 10 torr) in the temperature range 1400 - $1600 \mathrm{C}$ by pyrolysis of methyltrichlorosilane Residual stress is measured by noting the shape change occurring in a hollow silicon carbide cylinder when the cylinder is slit axially along its entire length. Of particular interest to Thermo Electron's hot shell effort were the following: 1) RPI grows their material at different temperatures and pressure than does Thermo Electron; 2) RPI grows their material on the inside diameter of a graphite cylinder, as opposed to Thermo Electon's growing it on the outside diameter; and 3) outward physical appearances and grain structures of the materials grown in both programs were very similar. 


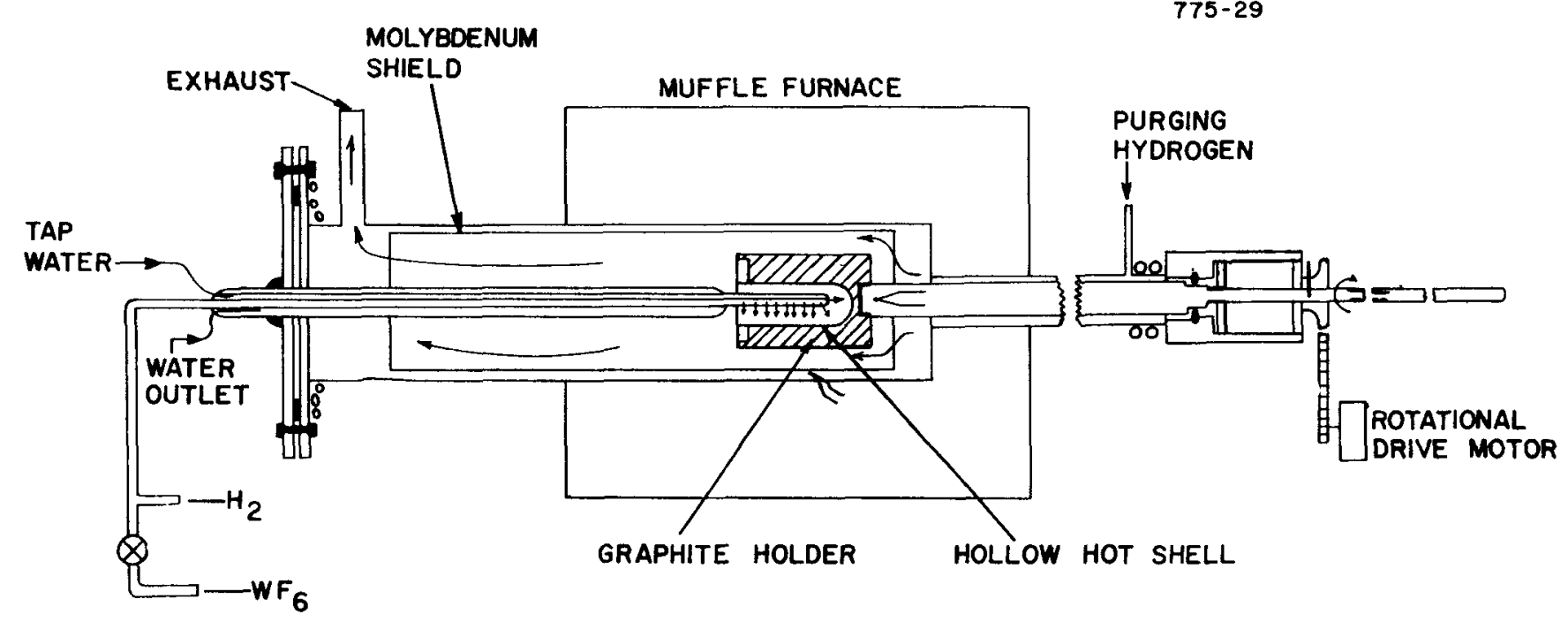

Figure IV-1. Apparatus for Chemical Vapor Deposition of Tungsten 
Simulated furnace testing continued under the following conditions: furnace gas temperature of $1300 \mathrm{C}(2370 \mathrm{~F})$, benzene combustion products flowing over the outside of hot shells, inside of shells evacuated to $10^{-7}$ torr. Table IV- 1 presents the status of these tests as of June 1, 1977. 
Table IV-1

SIMULATED FURNACE TESTS

(1 June 1977)

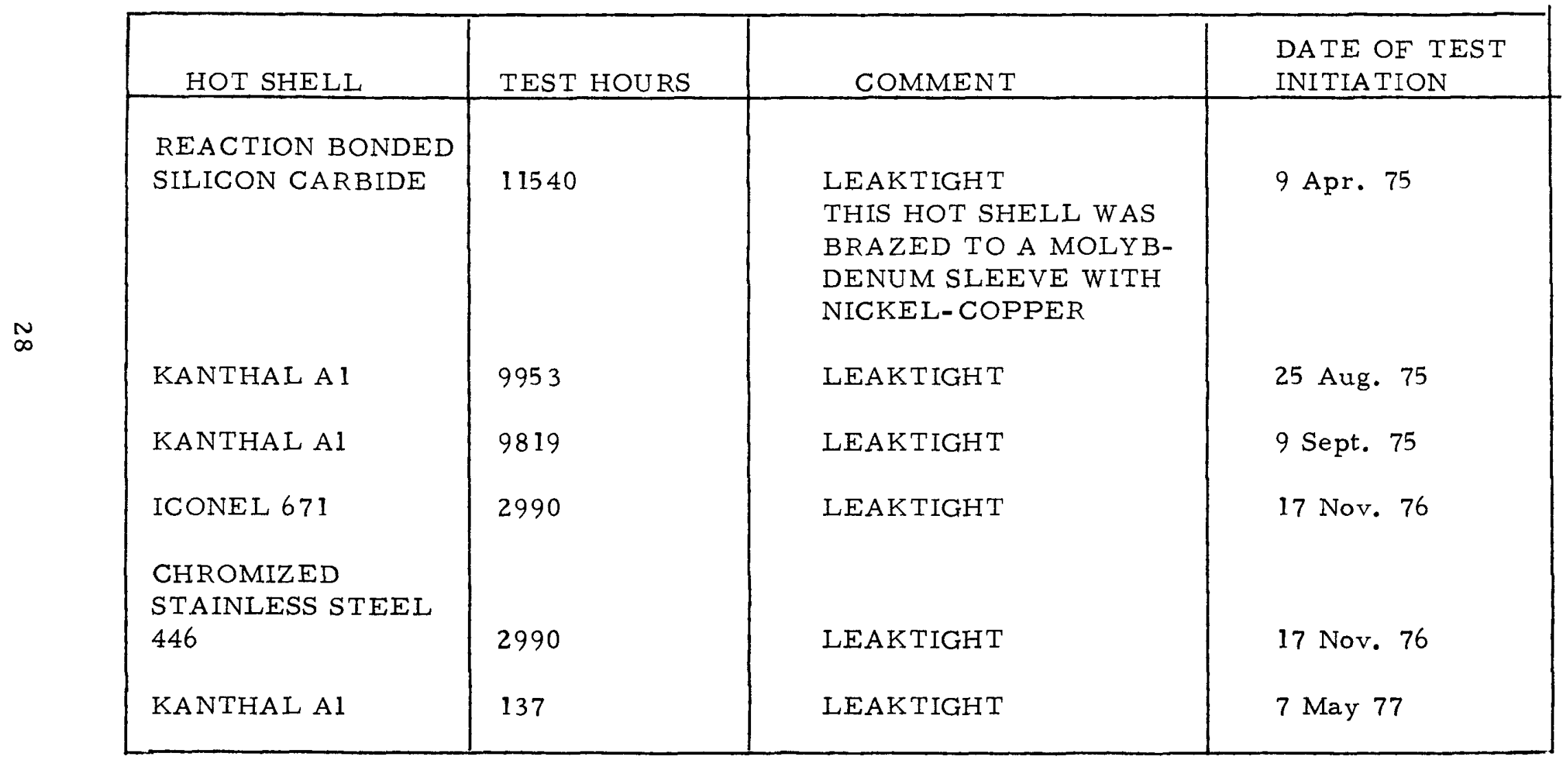


HOT SHELL MATERIALS

TECHNOLUGY II SUPPORT OF

ADVAIICED THERMIOHIC TECHNOLOGY

CONTRACT: $7070-4190-417$ 110d.\#3

PROGRESS REPORT NO: 3

REPORTING PERIOD: I May through 31 May 1977

PREPARED FO':

THERIAO ELECTROI CORRORATION

101 Firsl Avenue

Waltham, liassachusetts, 02754 


\subsection{INTRODUCTION}

This report describes the progress under contract 7070-4190-411 Mod. \#3 during the poriod of 1 May through 31 May 1977. It is submitted as a contract deliverable sumnarizing the monthly technical effort.

\subsection{PROGRAM OBJECTIVES AND TASKS}

The objective of this program is to develop, select and evaluate candidate alloys or alloy/coating combinations as protective cover materials for thermionic devices operating as energy converters (topping cycles) in the fossil fue 1 combustion product environment of steam power plants.

The program has the following tasks:

- Development of surface alloying process and evaluation of surface alloyed materials in sulfidizing-oxidizing environnents of $2200-2400^{\circ} \mathrm{F}$.

- Performance of long-term and thermal cyclic tests to determine the chemicalmetallurgical stability of promising materials.

- Investigation of fabrication process for producing hot shell shapes and fabrication of hot shell samples based on technical and economic merits as deliverables to Thermo Electron for testing.

\subsection{TECHNICAL PROGRESS}

During the reporting period several chromizing experiments and one hot corrosion test run were made. In chromizing, two new pack mixtures were tested: $45 \mathrm{Cr}-45 \mathrm{Al}_{2} \mathrm{O}_{3}-10 \mathrm{NH}_{4} \mathrm{Cl} ; 60 \mathrm{Cr}-20 \mathrm{CrCl}_{3}-18 \mathrm{Al}_{2} \mathrm{O}_{3}-2 \mathrm{NH}_{4} \mathrm{Cl}$. Thus far, none of the experiments showed a chromizing rate much above $0.25 \mathrm{mils}$ per hour. 
In a $2000^{\circ} \mathrm{F} 8$ hour cycle the maximum chromium thickness obtained to-date was 0.0015 inch $(1.5 \mathrm{mi} / \mathrm{s})$. A more desirable thickness would be $3-5 \mathrm{mils}$.

Hot corrosion test results (figure 1) hovever, show that even with a nominal 1 mil chromized layer the beneficial effects are conclusive. Chromized $446, \mathrm{HC}$ and HH exhibited gCod corrosion resistance comparable to INCO 671 and INCO 690 while the corresponding uncoated alloys corroded severely. (Figure 1).

The current intensive effort is to increase the chromizing rate to produce 3-5 mils of surface alloy coating on 446 type substrates within an 8-16 hour cycle. A number of chromium electrodeposited specimens on $446,309, \mathrm{HA}$ and $\mathrm{HC}$ steels have been prepared for comparison purposes. Diffusion heat-treatment will be done on some of the electroplated specimens before testing. In addition, plans are being made to prepare coated steel specimens with the following composition coatings by either cvo or plasma spray:

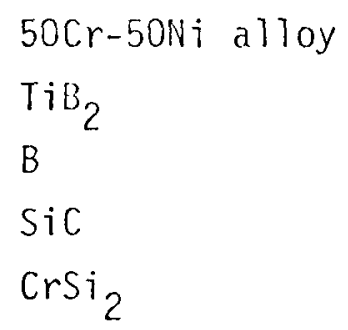

Two additional hot corrosion test facilities have been set up for long-tern and thermal cyclic tests. The next hot corrosion test (\#2) will include improved chromized specimens and chromium electrodeposited specimens at $2200^{\circ} \mathrm{F}$ for 100 hours:

INCO 671

INCO 690

446 chromized (1.5mil)

HC chromized ( $1.5 \mathrm{mil})$

309 chromized $(1.5 \mathrm{mil})$

446 chromium electrodeposited (4mil)

446 chromium electrodeposited (4mil) diffusion treated

$\mathrm{HC}$ chromium electrodeposited (4mil) diffusion treated

HA chromium electrodeposited (4mil) diffusion treated 

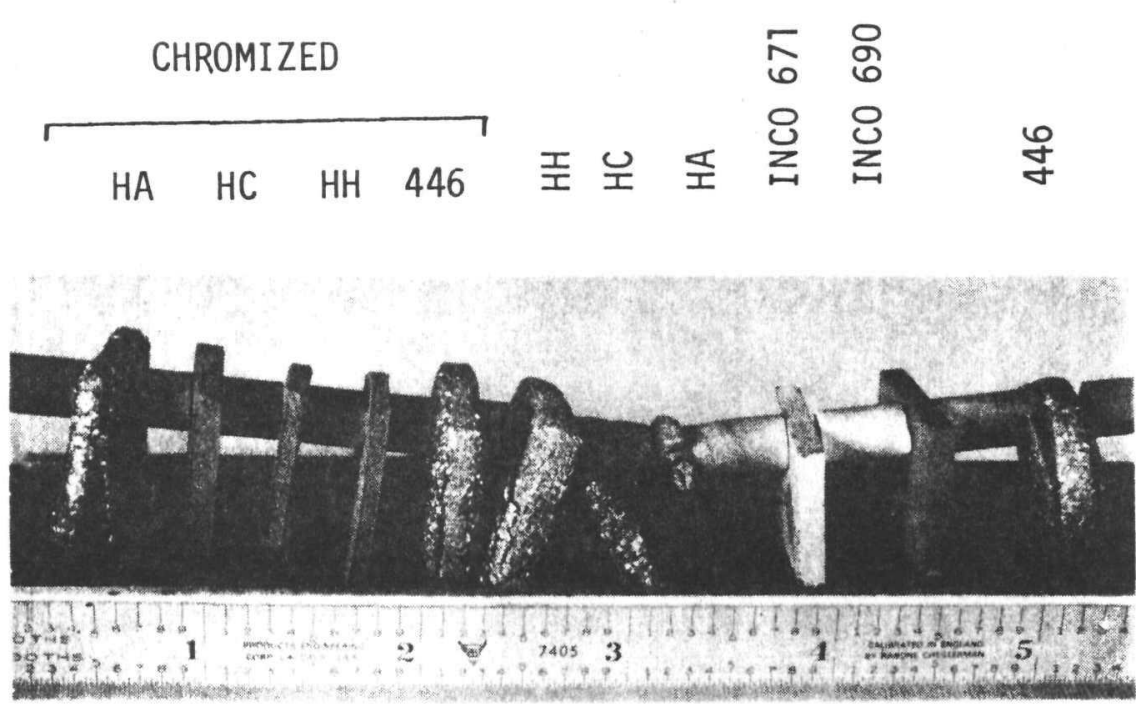

FIGURE 1: SPECIMENS FROM RUN \#1, $2200^{\circ} \mathrm{F}$ - 100 HOURS $3 \%$ EXCESS AIR GAS MIXTURE. NOTE DIFFERENCE BETWEEN UNTREATED AND CHROMIZED SPECIMENS 